ARGININE VASOPRESSIN (AVP) IN FETAL LAMBS \& RESPONSE TO BLOOD LOSS W.H. Drumond A.M. Rudolph, L.C.Keil \& i.A. Heymann. U. Ob-Gyn \& NASA-Ames Research Center, Moffett Field, Ca. The fetus appears to be capable of homeostatic regulation of its fluid environment in utero. Possible hormonal modulation mechanisms influencing cardiovascular homeos tas is include AVP, which in adult animals is released from the posterior pituitary in response to hyperosmolar stimulf or volume depletion. Fetal AVP production was studied in chronically prepared unstressed fetuses and in acutely hemorrhaged fetuses from 0.4 of gestation to term. Serum levels of AVP were measured by specific radioimmunoassay. Assay cross reactivity with fetal arginine vasotocin and angiotension 1 was negligible. In chronically catheterized fetuses, basal AVP levels rose from $0 \mathrm{pg} / \mathrm{ml}$ at gestation age (GA) $112 \mathrm{~d}$ to $2.4 \mathrm{pg} / \mathrm{ml}(5 \mathrm{mU} / \mathrm{ml})$ at $\mathrm{GA} 140 \mathrm{~d}$. Epidural anes thesia to the ewe and acute catheterization of the fetus was associated with mean fetal levels of $14.9 \mathrm{pg} / \mathrm{ml}$. In these fetuses, sequential hemorrhage of 5 to $20 \%$ of total blood volume resulted in an increase of serum AVP. Mean AVP levels for 4 fetuses 130-148 GA were $48.1 \mathrm{pg} / \mathrm{ml}$ after $5 \%$ bleeding, $200.1 \mathrm{pg} / \mathrm{ml}$ after $10 \%, 106 \mathrm{pg} / \mathrm{ml}$ after $15 \%$ and $151 \mathrm{pg} / \mathrm{ml}$ after $20 \%$. A very early gestation fetus (GA 59) had a higher basal level after anesthesia and exteriorization: $56.8 \mathrm{pg} /$ $\mathrm{ml}$. This increased only to $69.1 \mathrm{pg} / \mathrm{ml}$ after $10 \%$ hemorrhage. That such a large release of this membrane active hormone is present early in gestation when the kidneys are extremely immature, suggests that AVP may act to control water metabol ism at membrane surfaces other than renal in the fetal placental unit. Supported surfaces other than renal
by USPHS Grant HL 06285 .

200 EXPRESSIVE APHASIA IN CONGENITAL RUBELIA SYMDROME. Lytt I. Gardner and Phillip I. Nieburg. Dept. of Peds., StiNY, Upstate Med. Ctr., Syracuse, N.Y. Language disorders in children with congenital rubelia syndrome (CRS) have usually been associated with autism, deafness or mental retardation, or to some combination of these. The present report concerns a child with CRS and expressive aphasia pot attributable to the three named causes.

Th1s now 12 year old g1rl was born In Sept. 1964 to a mother who was exposed to and had symptoms consistent with rubella near the time of conception. Pregnancy lasted 42 weeks; birth wt. was $2380 \mathrm{gm}$ (older s1bs were 3600 and $4500 \mathrm{gm}$ ). No abnormal1t1es were $2380 \mathrm{gm}$ (older sibs were 360 and 450 fluids without difficulty; noted then or later. She could drink fluids without difficulty; she choked frequently on solids. There was dre-appropriate except for speech. She said "mama" at age 16 mos. but never progressed further. At age 4 a neurologist suggested an 1solated bulbar palsy as the cause of the speech d1sorder. EEG was normal. Hearing is entirely normal. She is in an age-appropriate grade in public school, communicating with the ald of the sign language public school, communicating with the her by volunteers. She 18 of the deaf, which has been taught to her by volunteers. She
aphasic with severe motor 1nvolvement of the 11 ps and tongue. Performance 18 good on non-verbal developmental tests.

In the evaluation of language disorders in chlldren with CRS 1solated neuromuscular disease such as shown by this patient should be considered.

\section{FERRITIN SYNTHESIS IN HUMAN EMBRYONIC AND FETAL} TISSUES. Jonathan D. Gitlin, Joan 1. Gitlin and children's hospital of Pittsburgh, Department of

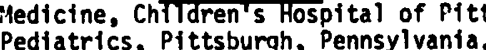

Ferritin synthesis by various tissues of the human conceptus Ferritin synthesis by various tissues of the human conceptus
was examined in the present study using tissue cultures. Normal embryonic and fetal tissues were obtained from 21 spontaneously or therapeutically aborted conceptuses of 29 days to 21 weeks of gestation. The tissues were cultured in the presence of ${ }^{14} \mathrm{C}$ amino acids and the culture fluids were examined for synthesized radioactive ferritin by means of immunodfffusion and autoradiography. Ferritin synthesis was detected in the earliest embryo studied, 29 days of gestation; this embryo was too small to permit culture of individual tissues and all tissues were cultured together. Ferritin synthesis by the liver and yolk sac was clearly estabi ished at the earliest stages in which these organs were cultured separately, 4.5 and 5.5 weeks of gestation, able in some embryos at 8.5 weeks and was established in this tissue and in the spleen by 11 weeks. The chronological develtissue and in the spleen by 11 weeks. The chronological deve opment of ferritin synthesis from liver and yolk sac to bone of hematopoiesis. Ferritin synthesis was noted in the stomach and duodenum at 8.5 weeks, but was not well established at these sites until 21 weeks, suggesting possible induction of ferritin synthesis in the latter organs through fetal swallowing of amniotic flutd containing transferrin iron.
202 DEVELOPMENTAL CHANGES IN THE PROPERTIES OF LTVER GUCURRONLTRANSFERASE IN RATS. Ruth Goldstein, university of California, Moffitt and San Francisco VA Hospitals, Departments of Pediatrics and Medicine, San Francisco.

The molecular basis for postnatal changes in glucuranyltransferase (GT) activity is not understood. The mechanisms underlying these changes were studied in fetal (F), newborn (N), and adult (A) rats using p-nitrophenol (PNP) as acceptor substrate. When assayed at 2 to $4 \mathrm{mM}$ UDPCA, GT activity in $F$ and $N$ was greater than in A. Kinetic analysis revealed that the apparent K for UDPGA at $0.4 \mathrm{mM}$ PNP was 4 to $6 \mathrm{mM}$ for $\mathrm{F}$ and $\mathrm{N}$, and 13 to it mM for $A$. When assayed at saturating concentrations of UDPGA, GT activities in $F, N$ and $A$ were equivalent. Hence, the differences in activity of $F, N$ and $A$ at 2 to $4 \mathrm{mM} \mathrm{UDPGA}$ are due to differences in affinity of GT for UDPGA. UDP-N-acetylgluoosamine (UDPNAG) is known to increase the affinity of GT for UDPGA in mature liver. UDPNAG increased GT activity 3 to 4fold in $A$ in the presence of 1 mM UDPGA, but had no effect in $F$ or N. However, an activating effect of UDPNAG on GT was observed in $\mathrm{N}$ when the concentration of UDPGA was reduced to that that developmental changes in symesthetional forms of GT. reflect the activities of different functional aorms of Small amounts of the A form of GT are present at 5 days post 20 days after birth.

203 RLEVATED CORD BLOOD FREE ERYTHROCYTE PORPHYRIN (PEP) - A SIGN OR "MASKED" IRON DEFICIENCY? Michael A. Gottuso, Barbara F. Oak1 and Prank A. Osk1. SUNYY, Upstate Medical Center, Syracuse, N.Y.

Elevations of FBP are recognized to be a lgn of both lead polsoning and 1ron deficlency. Cord blood FEP values were previously observed to be higher than those found in normal ch1ldren and adults. The mean cord blood FEP was $94 \mu \mathrm{gm} / 100 \mathrm{al}$ RBC's as contrasted with a value of $50+20$ in the older population. In Infante with elevated cord blood FEP values, blood leads were less than $15 \mathrm{\mu g} / \mathrm{dl}$. In further attempt to explain marked variations in cord blood FEP values, infants with high marked variations in cord blood FEP values, lnf ants with hish and low capecity performed. Twenty infants with PEP values of less than $55 \mu \mathrm{g} / 100 \mathrm{ml} \mathrm{RBC}$. had mean serum tron of $177 \mathrm{\mu g} / \mathrm{dl}$ and a mean transferrin saturation of $72 x$. In contrast, 10 infants with FEP values in excess of $125 \mu \mathrm{g} / 100 \mathrm{al} \mathrm{RBC}^{\prime}$, had a mean serum 1ron of $127 \mu \mathrm{g} / \mathrm{dl}$ and a transferrin saturation of infants with elevated PEPs. Although these levels of seruin Iron infants wth elevated se. andence of 1 ron deficiency in older Infants and children they evidence of 1 ron deficiency in older Infants and children the
ma in fact reflect suboptimal iron atores during a period of intense erythropolesis. Cord blood FEP determinatione could provide a simple means of detecting the infant at risk for the development of early Iron deficlency.
204 ALTERED ENZYME PROFILES IN OBESITY. M.R.C. 204 Greenwood, M.P. Cleary, D.Blase \& Jaticrase Genet1cs, Coll. Phys1c1ans \& Surgeons, N.Y.,N.Y. 10032 Early-onset obesity is a life long chronic disease, generally refractory to therapy, characterized both in man and rodents by hyperplasia and hypertrophy of ad1pocytes. A means of early diagnosis would be clinically very useful. Enzymatic changes have already been noted in the genet1cally obese $\operatorname{rat}(\mathrm{fa} / \mathrm{fa})$ vs 1 ts lean littermate( $\mathrm{Fa} /-)$. Elevated DNA polymerase and total thym1dine kinase(TK) activities were noted unt1l 26wks of age in $\mathrm{fa} / \mathrm{fa}$, but reached normal adult levels by $28 \mathrm{~d}$ in $\mathrm{Fa} /-$. In recent work $\mathrm{TK}$ has been separated by gel electrophoresis into 1 ts prollferative and nonproifferative variant forms. The proliferative:nonproliferative ratio is greater in $\mathrm{fa} / \mathrm{fa}$ vs $\mathrm{Fa} /-$ at 5 weeks. When hypertrophy is assessed by measuring lipoprotein lipase (LPL) act1vity, LPL per fat cell is elevated in $\mathrm{fa} / \mathrm{fa}$ rats at $5,10 \& 14 \mathrm{wk}$ of age. Further examination of the enzyme preparation Indicates that the Vmax 1s 10-fold greater in epididymal and retroperitoneal pads at 5 \&lowk in $\mathrm{fa} / \mathrm{fa}$ rats. Further study will be necessary to establish the Importance of these changes in the genesis of obesity. However since both TK and LPL can be measured in 20-40mg of adipose tissue, they may be useful tools in assessing the onset of obesity in needle biopsies from at-risk infants and children. 